NBER WORKING PAPER SERIES

\title{
PANDEMIC SCHOOLING MODE AND STUDENT TEST SCORES: EVIDENCE FROM US STATES
}

\author{
Clare Halloran \\ Rebecca Jack \\ James C. Okun \\ Emily Oster \\ Working Paper 29497 \\ http://www.nber.org/papers/w29497 \\ NATIONAL BUREAU OF ECONOMIC RESEARCH \\ 1050 Massachusetts Avenue \\ Cambridge, MA 02138 \\ November 2021
}

We are grateful to Hannah Orlove for excellent research assistance. The COVID-19 School Data Hub was produced with funding from Emergent Ventures at the Mercatus Center, the Chan Zuckerberg Initiative, and Arnold Ventures. Contact: Emily Oster at emily oster@brown.edu. The views expressed herein are those of the authors and do not necessarily reflect the views of the National Bureau of Economic Research.

At least one co-author has disclosed additional relationships of potential relevance for this research. Further information is available online at http://www.nber.org/papers/w29497.ack

NBER working papers are circulated for discussion and comment purposes. They have not been peer-reviewed or been subject to the review by the NBER Board of Directors that accompanies official NBER publications.

(C) 2021 by Clare Halloran, Rebecca Jack, James C. Okun, and Emily Oster. All rights reserved. Short sections of text, not to exceed two paragraphs, may be quoted without explicit permission provided that full credit, including $(\odot$ notice, is given to the source. 
Pandemic Schooling Mode and Student Test Scores: Evidence from US States

Clare Halloran, Rebecca Jack, James C. Okun, and Emily Oster

NBER Working Paper No. 29497

November 2021

JEL No. I14,I21,I24

\section{ABSTRACT}

We estimate the impact of district-level schooling mode (in-person versus hybrid or distance learning) on test scores. We combine Spring 2021 state standardized test score data with comprehensive data on schooling in the 2020-21 school year across 12 states. We find that pass rates declined compared to prior years and that these declines were larger in districts with less inperson instruction. Passing rates in math declined by 14.2 percentage points on average; we estimate this decline was 10.1 percentage points smaller for districts fully in-person. Changes in English language arts scores were smaller, but were significantly larger in districts with larger populations of students who are Black, Hispanic or eligible for free and reduced price lunch.

\author{
Clare Halloran \\ Brown University \\ clare.halloran@gmail.com \\ Rebecca Jack \\ University of Nebraska at Lincoln \\ $1400 \mathrm{R}$ St \\ Lincoln, NE 68588 \\ rebecca.s.jack@gmail.com
}

\author{
James C. Okun \\ MIT \\ jokun@mit.edu \\ Emily Oster \\ Brown University \\ Department of Economics \\ 64 Waterman Street \\ Providence, RI 02912 and \\ NBER \\ emily_oster@brown.edu
}

A Learning Mode Database is available at https://www.covidschooldatahub.com/ 


\title{
Pandemic Schooling Mode and Student Test Scores: Evidence from US States *
}

\author{
Clare Halloran \\ Rebecca Jack \\ James Okun \\ Brown University \\ University of Nebraska-Lincoln \\ MIT \\ Emily Oster \\ Brown University and NBER
}

November 14, 2021

\begin{abstract}
We estimate the impact of district-level schooling mode (in-person versus hybrid or distance learning) on test scores. We combine Spring 2021 state standardized test score data with comprehensive data on schooling in the 2020-21 school year across 12 states. We find that pass rates declined compared to prior years and that these declines were larger in districts with less in-person instruction. Passing rates in math declined by 14.2 percentage points on average; we estimate this decline was 10.1 percentage points smaller for districts fully in-person. Changes in English language arts scores were smaller, but were significantly larger in districts with larger populations of students who are Black, Hispanic or eligible for free and reduced price lunch.
\end{abstract}

\section{Introduction}

Over the course of the 2020-21 school year, students across the United States experienced educational disruptions as schools and districts alternated between learning modes in an effort to mitigate the transmission of Coronavirus Disease 2019 (COVID-19). Uncertainty about the role of schools in the spread of COVID-19 as well as the impact of different schooling modes forced school leaders to make difficult decisions about how to appropriately support both their students and staff (McLeod and Dulsky, 2021). School districts utilized a range of schooling modes (sometimes called "learning

\footnotetext{
${ }^{*}$ We are grateful to Hannah Orlove for excellent research assistance. The COVID-19 School Data Hub was produced with funding from Emergent Ventures at the Mercatus Center, the Chan Zuckerberg Initiative, and Arnold Ventures. Contact: Emily Oster at emily_oster@brown.edu.
} 
models") throughout the year: some remained closed and offered virtual learning options, others opened for full-time in-person learning, and some combined these approaches through a "hybrid" schooling mode (Kaufman and Diliberti, 2021). Approaches to both hybrid and virtual learning varied, including different numbers of days in school and variation in the degree of synchronous instruction (Marshall, Shannon, and Love, 2020).

There has been some effort to compare overall student learning during the pandemic to prepandemic years, without reference to schooling mode (Lewis et al., 2021). Other research has relied on parent or teacher perspectives of students outcomes based on reported schooling mode (Chen et al., 2021; Verlenden et al., 2021). To date, however, little is known about how outcomes vary for students by school districts' predominant schooling mode.

In this paper, we use data on district schooling modes alongside Spring 2021 test score data from 12 states to analyze the relationship between schooling mode and test scores. We estimate the relationship between the share of the year that in-person learning was offered (as opposed to hybrid or virtual learning) and student standardized test scores, both overall and interacted with district demographics. Our main regression specification uses a standard panel data approach, with data at the district-year level, to estimate the impact of the time spent in-person on 2021 test scores. These regressions include district-specific trends and a full set of demographics and year interactions.

We demonstrate first that, across all 12 states in our sample, there were large reductions in test scores between 2020-21 and previous years. The average decline in math is 14.2 percentage points, versus 6.3 percentage points in English language Arts (ELA). These changes are well outside typical year-on-year variation.

Following this, we show our main finding: the decline in students' 2021 test scores as compared to prior years was significantly larger in districts which offered less access to in-person schooling. For example, we estimate that offering full in-person instruction rather than fully hybrid or virtual instruction reduces test score losses in math by 10.1 percentage points (on the base of 14.2 percentage points). In ELA, the loss is reduced in fully in-person settings by 3.2 percentage points. These interactions between test score losses and schooling mode are highly significant.

We demonstrate, as well, that access to in-person learning varied by demographics and baseline test scores. Districts with lower baseline test scores and a higher share of Black students offered less in-person learning. Within states, districts with a higher share of Hispanic students also offered less in-person learning (although across states this effect is reversed).

Finally, we observe that the impact of access to in-person learning on 2021 test scores also 
varies by subject and demographics. Specifically, among districts with a larger share of Black and Hispanic students, districts with less in-person schooling saw a greater decline in ELA test scores than those with more in-person schooling. Although the impact of schooling mode on ELA is fairly small for districts which are majority white, it is large for those districts with a majority of students of color. Meanwhile, the impact of access to in-person learning had a similar effect on math scores for all districts, regardless of their racial composition.

A key consideration for our results is the role of test participation. Test participation was lower in the 2021 testing cycle than previous years. This was true for several reasons, one of which includes changes in federal participation requirements (Gewertz, 2021). According to state reports, the lost participation seems to disproportionately come from groups with generally lower test scores 1 . this would suggest our estimates understate test score losses.

To account for this, we use data on participation rates and re-estimate our models with varying assumptions about the performance of students who do not participate in testing. We find our results are robust. In our preferred specification, in which we calibrate the relationship between participation and counterfactual test scores, we find our baseline results underestimate both overall test score losses and the impact of in-person learning in ameliorating them.

A second concern is that it is not variation in schooling mode but rather other pandemic-related factors that drive our results, such as changes in parents' or caregivers' working conditions due to the pandemic, changes in access to child care, or changes in access to other services such as tutoring resources. In general, districts were more likely to offer in-person learning in areas with higher COVID-19 rates, suggesting the pandemic itself is a confound in the other direction. Nonetheless, given that the lack of in-person schooling was also likely associated with other lockdown behaviors, it is challenging to fully separate these effects.

We contribute to a large literature on how students' time out of school, typically due to summer break, impacts their academic achievement (McCombs et al., 2011; Alexander et al., 2016; von Hippel, Workman, and Downey, 2018). In their synthesis of the research on summer learning loss (SLL), McCombs and colleagues (2011) conclude that while all students experience summer learning loss, on average, this is particularly true for low-income students, and that losses accumulate over time. Other research has focused on learning disruptions resulting from long and unplanned school closures from events such as weather emergencies (Harmey and Moss, 2021).

1. See, e.g., Colorado Department of Education, 2021; Connecticut State Department of Education, 2021; Hanson, 2021; Hilton and Linnane, 2021; Littlehales, 2021; Ohio Department of Education, 2021; Rhode Island Department of Education, 2021 
More narrowly, we contribute to the small but growing literature on the impacts of the COVID19 schooling disruptions on students (Angrist et al., 2020; Bacher-Hicks et al., 2021; Dee et al., 2021; Musaddiq et al., 2021). In many cases, these papers highlight the possibility of significant inequalities in schooling losses during the pandemic (Kuhfeld et al., 2020; Kuhfeld and Tarasawa, 2020; Azevedo et al., 2021; Wyse et al., 2020; Fuchs-Schundeln et al, 2021), although they have limited data on outcomes. Of note are several papers which use test scores to directly study impacts of Spring 2020 closures on learning, largely in Europe (Tomasik et al., 2021; Engzell et al., 2021; Ardington et al., 2021; Contini et al., 2021; Maldonado and De Witte, 2021; Schult and Linder, 2021). Individually and in a systematic review, these papers tend to find significant learning losses as a result of limited in-person schooling access (Hammerstein et al., 2021; Storey and Zhang, 2021).

Relative to this existing literature, the wide variation in schooling access in the United States provides both more variation to exploit and a longer period of disrupted schooling.

Overall, our data suggest significant learning losses as measured by state assessments as a result of the pandemic, and larger losses in districts with less access to in-person learning. From a policy standpoint, our results highlight the non-health implications of the pandemic, which may be longlasting. There is significant funding at both the federal and state levels to address these issues; our findings suggest the possibility of targeting certain districts and students in these efforts. These data also highlight the value of in-person learning and may provide a caution when considering school closures in the future.

\section{Data}

Our analyses use three sources of data: 1) district-level schooling mode data from the 2020-21 school year; 2) district-level test score data from 2015 to 2021; and (3) demographic data from the NCES. We explain these data sources below.

\subsection{Schooling Mode Data}

District-level schooling mode data are drawn from the COVID-19 School Data Hub (CSDH). This is a public database, produced by our research team, which uses state-sourced data to document the schooling modes used by school districts during the 2020-2021 school year.

The CSDH sources raw data from State Education Agencies on schooling modes across schools or 
districts over the 2020-21 school year. ${ }^{2}$ The CSDH reviewed all school or district-level information and classified each school or district time period as: 1) "in-person" (all or most students had access to traditional, 5-day-per-week, in-person instruction); 2) "virtual" (all or most students received instruction online, five days a week); and 3) "hybrid" (schooling modes that did not fall into one of these approaches). More details about the data construction in each state are available at the $\mathrm{CSDH} 3$

We included states in our analyses if the state had schooling mode available during the 2020-21 school year. When schooling mode was available at the school district level only, we used this mode in our analyses. In cases where schooling mode was available at the school or district-grade-band level, we calculate an enrollment-weighted average across schools or grade levels.

Our resulting data file is at the district-time period level. This classification represents our best attempt at capturing the typical schooling mode for students in a particular district and time period. However, this does not mean that this was the only way that students learned within a district, as changes occurred on a daily basis throughout the year at the district, school, and classroom level due to county-level COVID-19 case rates, school- and district-level quarantine procedures, and close-contact policies.

\section{$2.2 \quad$ Test Score Data}

We draw test score data from state-level testing in spring 2021. We included states in the analysis if they met the following test score criteria: 1) at least 2 years of pre-pandemic test data; 2) No significant testing changes over this period, and 3) statewide 2021 participation rates above $50 \%$. We focus on test scores for grades 3 through 8 in English language arts (ELA) and math. Our primary outcomes are subject-area pass rates, which measure the share of students who score proficient or above in ELA or math on state assessments. We present each state's testing details in Appendix B.

Our final sample includes 12 states: Colorado, Connecticut, Florida, Massachusetts, Minnesota, Nevada, Ohio, Rhode Island, Virginia, West Virginia, Wisconsin and Wyoming. In several of these cases, states have produced reports documenting learning losses using these raw data (Colorado Department of Education, 2021; Connecticut State Department of Education, 2021; Hanson, 2021; Hilton and Linnane, 2021; Littlehales, 2021; Ohio Department of Education, 2021; Rhode Island

2. The CSDH also contains data on student enrollment by schooling mode, if available from State Education Agencies. We do not use those data here.

3. https://www.covidschooldatahub.com/ 
Department of Education, 2021).

Of note is the fact that participation rates for tests in most states in spring 2021 were lower than in previous years. In a robustness analysis we use test participation rates to create bounds.

\subsection{Demographic and Pandemic Data}

In addition to these primary data sources, we draw information on school demographics from the National Center for Education Statistics (NCES). These data include information on the share of enrolled students by race and ethnicity as well as the share of students who are eligible for free and reduced price lunch (FRPL)-eligible. NCES also provides enrollment data; we use 2019-20 enrollment data as it is the most recent available. To capture the possible role of variation in COVID-19 case rates in driving district opening decisions, we use district-level COVID-19 case numbers from USA Fact:4. We focus on the average level of COVID-19 over school year in the central zip code of the school district, and the rate in August 2020, around school opening.

\subsection{Summary Statistics and Determinants of Schooling Mode}

Table 1 shows each state's summary statistics on schooling mode, pass rates, and demographics. Of the states in our analyses, in-person learning rates are highest in Florida and Wyoming, and lowest in Minnesota and Virginia. Virginia and Colorado also have the highest share of district-time spent in fully virtual learning. Across states, pass rates are, on average, lower in 2021 than 2019.

Table 2 estimates the relationship between the share of time a district offered in-person learning and the district's pre-pandemic test scores, demographics, and COVID-19 rates. Columns (1) and (2) estimate these regressions without state fixed effects, and Columns (3) and (4) include state fixed effects.

Overall, higher baseline test scores appear to be associated with greater in-person learning shares; this is especially true within states. A greater share of Black students in a district is associated with less in-person learning, both within and across states. In contrast, conditional on race shares, a higher share of students with FRPL status correlates with greater in-person learning. The share of Hispanic students in the district correlates positively with in-person share across states, but negatively within states; this reflects overall access differences across the states in our sample (i.e. a high in-person rate in Florida).

4. Available at https://usafacts.org/. 
Focusing on the within-state results, the overall picture suggests that more vulnerable districts

- lower prior test scores, more minority students - were less likely to have access to in-person schooling.

On pandemic metrics, we find that both within and across states, higher case rates (on average or in August) were associated with greater in-person schooling during the year. Much has been written on the possible role of schools in driving COVID-19 cases, most of which suggests schools were not significant drivers of COVID-19 (Goldhaber et al., 2021; Harris et al., 2021; UNICEF, 2020). The positive correlation here likely reflects differences in other pandemic restrictions which were correlated with schooling mode choice and influenced COVID-19 rates.

\section{Results}

We turn now to using the above data to estimate the impact of the pandemic schooling mode on student test scores. Our primary treatment is the share of the school year that districts offered full-time in-person learning options, with the untreated group being a combination of hybrid and fully virtual districts. Effectively, we can view these analyses as identifying the possible losses resulting from deviation from a traditional school schedule, characterized by in-person learning.

\subsection{Overall Test Score Changes}

Figure 1 illustrates the changes in pass rates across states during the pandemic period (the 2020-21 school year) and in several previous periods (the 2015-16 school year through 2018-19). Panel A shows the scores in math and Panel B presents the scores in ELA. The solid triangles represent the change in pass rates between the 2018-19 school year (the last pre-pandemic year) and the 2020-21 school year. The open circles show prior year-on-year changes.

Our analysis finds a decline in pass rates from the 2018-19 school year to the 2020-21 school year in all states. The decline ranges from -31.9 percentage points (Virginia, math) to -2.3 percentage points (Wyoming, ELA). Based on the prior year changes, typical year-on-year variation is very small. The pandemic year is a significant outlier.

The changes in pass rates for math (Panel A) are considerably larger than the changes in scores for ELA (Panel B). This is broadly consistent with a larger literature which shows math scores are more responsive to schooling differences (Betts and Tang, 2011; Angrist et al., 2013). 


\subsection{Schooling Mode and Test Score Changes}

To analyze changes by schooling mode, we divide districts into three groups: districts that offered in-person learning to students for at least two-thirds of the school year ("Most In-Person"), districts that offered in-person learning to students between one-third and two-thirds of the year ("Intermediate In-Person"), and districts that offered in-person learning to students for less than one-third of the school year ("Least In-Person"). We then analyze year-on-year changes in test scores for each group, by state 5

Panel A of Figure 2 shows the year-on-year changes in math test scores by group for prepandemic years (left figure) and for the pandemic year (right figure). In most cases, the test score declines in the pandemic year are larger in the districts with less in-person instruction. This difference is largest in Virginia. There is no evidence that this pattern aligns with the pre-pandemic years. Prior year-on-year changes do not seem to systematically vary with 2020-21 schooling mode.

Panel B shows the results for ELA. While the overall changes are smaller in ELA as compared to math, the pattern is similar.

We note that the states in the graph are organized left-to-right by the state-level share of inperson instruction. In addition to the within-state variation, there appears to be some relationship between average test score declines and average in-person share by state. In both subjects, there are sizable reductions in scores even among areas which have the most in-person instruction. Locations places with less in-person schooling drop more, but the overall test score reductions go beyond virtual learning.

These graphs look at changes in scores across years; one interpretation of the larger reductions in districts with less in-person learning is that they started at higher pass rates, on average. However, this is inconsistent with the evidence in Table 2, which demonstrates that higher pre-pandemic test scores are associated with greater in-person learning access.

Next, we estimate standard difference-in-difference regressions at the district-year level, including district-specific trends and interactions between district demographics and time (equation (1) below). In addition to the primary regressions, we analyze the relative impact of schooling mode by demographics (equation (2) below). To do so, we include an interaction of in-person share, a dummy for 2021 and either (a) the share of Black or Hispanic students or (b) the share of students eligible for free or reduced price lunch.

5. We exclude state-groups which contain fewer than $5 \%$ of districts; in addition, Florida is excluded as it is entirely in the "Most In-Person" group. All districts, however, are included in regression analyses. 
More specifically, our estimating equations can be stated:

$$
\begin{aligned}
& y_{d t}=\alpha p_{d} 1(t=2021)+\beta_{t} X_{d t}+\phi_{d} t+\gamma_{t}+\zeta_{d}+\epsilon_{d t} \\
& y_{d t}=\left(\alpha p_{d}+\theta p_{d} x_{d}+\varphi x_{d}\right) 1(t=2021)+\beta_{t} X_{d t}+\gamma_{t}+\zeta_{d}+\epsilon_{d t}
\end{aligned}
$$

where $d$ represents districts, $t$ is the year, $y_{d t}$ is the pass rate for a specific subject in district $d$ during year $t, p_{d}$ is the share of days in-person in 2021, $X_{d t}$ is a matrix of district $d$ 's demographics (share White, share Black, share Hispanic, and share FRPL) in year $t, \phi_{d} t$ is a district specific linear time trend, $\gamma_{t}$ is a time fixed effect, $\zeta_{d}$ is a district fixed effect, and $\epsilon_{d t}$ is a idiosyncratic shock to pass rates in district $d$ during year $t$. In the second model, $x_{d}$ is a specific demographic characteristic (either share of students of color or share FRPL).

We present these analyses in Table 3 , with Columns (1)-(3) focusing on math and Columns (4)-(6) on ELA. Columns (1) and (4) echo the results from Figure 2 , The regression suggests that moving a district from $0 \%$ to $100 \%$ access to in-person learning would mitigate test score loss by 10.1 percentage points in math and 3.7 percentage points in ELA. Both are highly significant.

In Columns (2) and (5), we explore interactions with the share of Black and Hispanic students in the district. In the case of math, there is no significant difference in the effect of in-person learning by districts' race or ethnicity. In ELA, however, we find that the benefit of in-person learning is significantly higher in districts with a higher share of students who are Black or Hispanic.

Aggregating the coefficients together, we find that for a district with no Black or Hispanic students, moving from fully in-person to only hybrid or virtual would be expected to decrease pass rates by 4.3 percentage points. However, for a district with a $50 \%$ Black and Hispanic student population, that same move from fully in-person to fully not in-person would be expected to decrease pass rates by 9.0 percentage points.

Columns (3) and (6) do the same for FRPL-eligible students. In this case, students in districts with a larger share of FRPL-eligible students benefit more from in-person learning in both math and ELA. The relative gains are larger in ELA versus math. For a district with no FRPLeligible students, our estimates suggest full in-person learning would reduce test score losses by 2.9 percentage points. However, for a district where $100 \%$ of students were FRPL-eligible, these advantage to full in-person learning is 10.3 percentage points.

Putting this together, the regressions paint a picture in which average test score losses are larger 
in math as compared to ELA. Yet, we see substantial ELA losses among districts with larger Black, Hispanic, or FRPL-eligible student populations.

We focus here on in-person learning, with the omitted category as a combination of hybrid and distance learning. Appendix Table 1 replicates Columns (1) and (4) of Table 3 including both in-person and hybrid learning shares; the omitted category is distance learning. We observe an intermediate coefficient on hybrid learning share, consistent with the observation that hybrid districts had an intermediate amount of school time.

\subsection{Robustness: Participation Changes}

A key empirical issue in evaluating these changes is the role of participation rates. In all states, test participation was lower in the pandemic year than in previous years. We observe that the 2021 participation rate drops are typically larger in districts with more virtual learning. One interpretation of both lower pass rates overall and the differences by mode is that they are driven by these participation changes. To evaluate this, we consider the explicit assumptions which drive our conclusions.

Consider that there exists an underlying distribution of test scores in the entire population of students, whether or not they take the test. In a typical non-pandemic year, test participation rates are extremely high, and it is reasonable to assume we see virtually the entire distribution. In 2021, test taking rates are lower (see Appendix B for details by state). If the 2021 test-takers are chosen at random from the distribution, however, then the changes we observe reflect the overall distribution and are unbiased.

If there is negative selection in test-takers - that is, if the bottom of the distribution is more likely to test - then our estimates will overstate the test score losses. In contrast, if there is positive selection in test-takers - if the bottom of the distribution is less likely to test - then our primary estimates will understate test score losses. We explore robustness to this in three ways: 1) by discussing what is known about test score selection, 2) by using a back of the envelope selection assumption, and 3) by modeling participation selection explicitly.

On the first point: based on state reports, participation declines during the pandemic appear to be larger in more vulnerable groups (Colorado Department of Education, 2021; Connecticut State Department of Education, 2021; Hanson, 2021; Hilton and Linnane, 2021; Littlehales, 2021; Ohio Department of Education, 2021; Rhode Island Department of Education, 2021). This includes students from lower socioeconomic status (SES) backgrounds, English language learners (ELL), 
and others. These groups typically have lower test scores than other student subgroups, such as their higher SES peers or students who are English proficient. To the extent that these are the excluded groups, our estimates will understate test score losses.

This argument suggests our results may be conservative. To be more precise, we consider three approaches to modeling the counterfactual test scores for the absent individuals. First, we create a bound which assumes a form of positive selection in test takers. Specifically, we assume those who do not take the test are drawn randomly from a distribution with a one standard deviation lower test score than the district mean. Second, we create a parallel bound which assumes negative selection in test takers. This assumes those who do not take the test are drawn randomly from a distribution with a one standard deviation higher test score higher than the district mean.

Our preferred approach is the third, which explicitly models the relationship between pass rates and participation. Conceptually, we attempt to estimate the relationship between participation rates and pass rates, and then infer the expected pass rate if participation was higher. Practically, we do this by regressing pre-pandemic pass rates on pandemic-year participation rates, interacted with schooling mode. These regressions also control for schooling mode and for a rich set of demographics. In the end, the regressions aims to estimate the expected change in pass rate with a change in participation rate. We then apply these coefficients to the 2021 data to calculate a counterfactual pass rate under full participation.

Appendix Figure 1 replicates Figure 1 for the pandemic year, showing the changes under our baseline assumption and the three alternative assumptions about participation; note these regressions exclude Virginia, where we do not currently have participation data. Under all three alternative assumptions, we continue to observe declines in test scores. Of note, the calibrated counterfactual is close to the positive selection bound, suggesting that the calibration supports the observation that test takers were positively selected.

Appendix Table 2 replicates Columns (1) and (4) of Table 3 under these varying assumptions. (The baseline effect is lower due to the exclusion of Virginia). The calibrated assumption suggests a larger advantage for in-person districts, which is consistent with positive selection of those taking the test. That is: the model underlying the calibrated assumption implies the marginal participants in the less-in-person districts would be expected to perform worse.

If we assume significant negative selection in test-takers, the effect of in-person learning is eliminated. This is important in illustrating the possible sensitivity of results, although we emphasize that both the state-level reports and the calibration point to positive selection in testers. 
Overall, we suggest based on this analysis that, if anything, the estimates we present in the baseline model in Table 3 may understate both the overall test score declines and the relative importance of in-person learning in stemming them.

\section{Discussion and Conclusion}

A remaining key threat to the validity of these results is endogeneity in schooling mode. This is the concern that districts with less in-person learning were more affected by other aspects of the pandemic. The pre-pandemic data in Figure 2 does not suggest differential pre-trends, but cannot speak to changes which resulted from the pandemic.

The most obvious concern is that less in-person learning may reflect higher community COVID19 rates, and that the health impacts of the COVID-19 pandemic are directly driving students' academic outcomes. However, this explanation does not align with the fact that in-person learning shares are actually higher in areas with higher COVID-19 rates.

Alternatively, given the clustering of lockdown measures, there is a concern that other non-school lockdowns - such as closures of local businesses or after-school activities - impacted learning. If this were the case, it will bias our results. Given the co-linearity between these restrictions, it is difficult to separate schooling changes from these other pandemic-related changes.

Taken together, the data here suggest that there were considerable declines in test scores overall during the 2020-21 school year, and these declines were larger in school districts with less in-person instruction. There are consequences for inequality in outcomes in these results. Students in districts with larger populations of Black and Hispanic students, for example, were less likely to have access to in-person learning. In addition, in ELA in particular, the consequences of distanced learning were larger in districts with these demographics.

Test scores are only one measure of student learning during the 2020-21 school year. This paper cannot capture ways that students learned that were not reflected on such assessments; we also cannot account for pandemic-related changes in students' lives beyond schooling mode. However, these results can serve as a starting point for education leaders and policymakers as they weigh where to target funding moving forward in order to support student learning. Specifically, our analyses suggest that a focus on areas which had less in-person learning over the 2020-21 school year would be critical. More generally, our analyses demonstrate that that virtual or distanced schooling modes cannot support student learning in the same way as in-person schooling. As such, 
educational impacts of schooling mode on students' learning outcomes should be a critical factor in policy responses to future pandemics or other large-scale schooling disruptions. 


\section{References}

Alexander, Karl, Sarah Pitcock, and Matthew C Boulay. 2016. The summer slide: What we know and can do about summer learning loss. Teachers College Press.

Angrist, Joshua D, Parag A Pathak, and Christopher R Walters. 2013. "Explaining charter school effectiveness". American Economic Journal: Applied Economics 5 (4): 1-27.

Angrist, Noam, Peter Bergman, and Moitshepi Matsheng. 2020. School's out: Experimental evidence on limiting learning loss using "low-tech" in a pandemic. Technical report. National Bureau of Economic Research.

Ardington, Cally, Gabrielle Wills, and Janeli Kotze. 2021. "COVID-19 learning losses: Early grade reading in South Africa". International Journal of Educational Development 86:102480.

Azevedo, João Pedro, Amer Hasan, Diana Goldemberg, Koen Geven, and Syedah Aroob Iqbal. 2021. "Simulating the potential impacts of COVID-19 school closures on schooling and learning outcomes: A set of global estimates". The World Bank Research Observer 36 (1): 1-40.

Bacher-Hicks, Andrew, Joshua Goodman, and Christine Mulhern. 2021. "Inequality in household adaptation to schooling shocks: Covid-induced online learning engagement in real time". Journal of Public Economics 193:104345.

Betts, Julian R, and Y Emily Tang. 2011. "The Effect of Charter Schools on Student Achievement: A Meta-Analysis of the Literature." Center on Reinventing Public Education.

Chen, Li-Kai, Emma Dorn, Jimmy Sarakatsannis, and Anna Wiesinger. No date. "Teacher survey: Learning loss is global-and significant". mckinsey.com.

Contini, Dalit, Maria Laura Di Tommaso, Caterina Muratori, Daniela Piazzalunga, and Lucia Schiavon. 2021. The COVID-19 pandemic and school closure: learning loss in mathematics in primary education. Technical report. Collegio Carlo Alberto.

Cooper, Harris, Barbara Nye, Kelly Charlton, James Lindsay, and Scott Greathouse. 1996. "The effects of summer vacation on achievement test scores: A narrative and meta-analytic review". Review of educational research 66 (3): 227-268. 
Dee, Thomas, Elizabeth Huffaker, Cheryl Phillips, and Eric Sagara. 2021. The revealed preferences for school reopening: Evidence from public-school disenrollment. Technical report. National Bureau of Economic Research.

Dorn, Emma, Bryan Hancock, Jimmy Sarakatsannis, and Ellen Viruleg. 2020. "COVID-19 and learning loss - disparities grow and students need help". McKinsey 6 Company, December 8.

Education, Colorado Department of. August 2021. News release - statewide assessment results show decreased participation, lower CMAS scores than previous years. Technical report.

Education, Connecticut State Department of. August 2021. Statewide Summative Assessment Report 2020-21. Technical report.

Education, Ohio Department of. September 2021. Data insights: Evidence of the pandemic's impact on students in 2020-2021. Technical report.

Education, Rhode Island Department of. 2021. English language arts and mathematics assessment results 2021. Technical report.

Engzell, Per, Arun Frey, and Mark D Verhagen. 2021. "Learning loss due to school closures during the COVID-19 pandemic". Proceedings of the National Academy of Sciences 118 (17).

Ertem, Zeynep, Elissa M Schechter-Perkins, Emily Oster, Polly van den Berg, Isabella Epshtein, Nathorn Chaiyakunapruk, Fernando A Wilson, Eli Perencevich, Warren BP Pettey, Westyn Branch-Elliman, et al. 2021. "The impact of school opening model on SARS-CoV-2 community incidence and mortality". Nature Medicine, 1-7.

Fuchs-Schündeln, Nicola, Dirk Krueger, Andre Kurmann, Etienne Lale, Alexander Ludwig, and Irina Popova. 2021. The Fiscal and Welfare Effects of Policy Responses to the Covid-19 School Closures. Technical report. National Bureau of Economic Research.

Gewertz, Catherine. 2020. "Instruction during COVID-19: Less learning time drives fears of academic erosion". Education Week.

Goldhaber, Dan, Scott A Imberman, Katharine O Strunk, Bryant Hopkins, Nate Brown, Erica Harbatkin, and Tara Kilbride. 2021. To what extent does in-person schooling contribute to the spread of COVID-19? Evidence from Michigan and Washington. Technical report. National Bureau of Economic Research. 
Hammerstein, Svenja, Christoph König, Thomas Dreisörner, and Andreas Frey. 2021. "Effects of COVID-19-Related School Closures on Student Achievement-A Systematic Review".

Hanson, Melissa. September 2021. MCAS scores fell during COVID but decrease fairly even across racial, ethnic groups. Technical report.

Harmey, Sinéad, and Gemma Moss. 2021. "Learning disruption or learning loss: using evidence from unplanned closures to inform returning to school after COVID-19". Educational Review, $1-20$.

Harris, Douglas N, Engy Ziedan, and Susan Hassig. 2021. "The effects of school reopenings on COVID-19 hospitalizations". National Center for Research on Education Access and Choice.

Hilton, AnnMarie, and Rory Linnane. 2021. Fewer Wisconsin students took last year's standardized tests. those who did take them fared worse than usual. Technical report.

Hippel, Paul T von, Joseph Workman, and Douglas B Downey. 2018. "Inequality in reading and math skills forms mainly before kindergarten: A replication, and partial correction, of "Are schools the great equalizer?"”. Sociology of Education 91 (4): 323-357.

Kaufman, Julia H, and Melissa Kay Diliberti. 2021. "Divergent and Inequitable Teaching and Learning Pathways during (and Perhaps Beyond) the Pandemic: Key Findings from the American Educator Panels Spring 2021 COVID-19 Surveys." RAND Corporation.

Kerry, Trevor, and Brent Davies. 1998. "Summer learning loss: The evidence and a possible solution". Support for Learning 13 (3): 118-122.

Kuhfeld, Megan, James Soland, Beth Tarasawa, Angela Johnson, Erik Ruzek, and Jing Liu. 2020. "Projecting the potential impact of COVID-19 school closures on academic achievement". Educational Researcher 49 (8): 549-565.

Kuhfield, Megan, and Beth Tarasawa. 2020. "The COVID-19 Slide: What Summer Learning Loss Can Tell Us about the Potential Impact of School Closures on Student Academic Achievement. Brief." NWEA.

Lewis, K, M Kuhfeld, E Ruzek, and Andrew McEachin. 2021. Learning during COVID-19: Reading and math achievement in the 2020-21 school year. 
Littlehales, Alex. August 2021. COVID-19 pandemic affected scores, participation of standardized testing in Virginia. here's how. Technical report.

Maldonado, Joana Elisa, and Kristof De Witte. 2021. "The effect of school closures on standardised student test outcomes". British Educational Research Journal.

Marshall, David T, David M Shannon, and Savanna M Love. 2020. "How teachers experienced the COVID-19 transition to remote instruction". Phi Delta Kappan 102 (3): 46-50.

McCombs, Jennifer Sloan, Catherine H Augustine, and Heather L Schwartz. 2011. "Making summer count: How summer programs can boost children's learning".

McLeod, Scott, and Shelley Dulsky. 2021. "Resilience, Reorientation, and Reinvention: School Leadership During the Early Months of the COVID-19 Pandemic". In Frontiers in Education, 6:70. Frontiers.

Musaddiq, Tareena, Kevin M Stange, Andrew Bacher-Hicks, and Joshua Goodman. 2021. The Pandemic's effect on demand for public schools, homeschooling, and private schools. Technical report. National Bureau of Economic Research.

Schult, Johannes, and Marlit Annalena Lindner. 2021. "Did students learn less during the COVID19 pandemic? Reading and mathematics competencies before and after the first pandemic wave".

Storey, Nathan, and Qiyang Zhang. 2021. "A Meta-analysis of COVID Learning Loss".

Tomasik, Martin J, Laura A Helbling, and Urs Moser. 2021. "Educational gains of in-person vs. distance learning in primary and secondary schools: A natural experiment during the COVID19 pandemic school closures in Switzerland". International Journal of Psychology 56 (4): 566576.

Verlenden, Jorge V, Sanjana Pampati, Catherine N Rasberry, Nicole Liddon, Marci Hertz, Greta Kilmer, Melissa Heim Viox, Sarah Lee, Neha K Cramer, Lisa C Barrios, et al. 2021. "Association of children's mode of school instruction with child and parent experiences and well-being during the COVID-19 pandemic - COVID experiences Survey, United States, October 8-November 13, 2020". Morbidity and Mortality Weekly Report 70 (11): 369.

Werner, Katharina, and Ludger Woessmann. 2021. "The Legacy of Covid-19 in Education". 
Wyse, Adam E, Eric M Stickney, David Butz, Amanda Beckler, and Catherine N Close. 2020. "The potential impact of COVID-19 on student learning and how schools can respond". Educational Measurement: Issues and Practice 39 (3): 60-64. 


\section{$5 \quad$ Tables and Figures}

\section{Figure 1: Pass Rate Changes by Subject and State}

(a) Math Scores

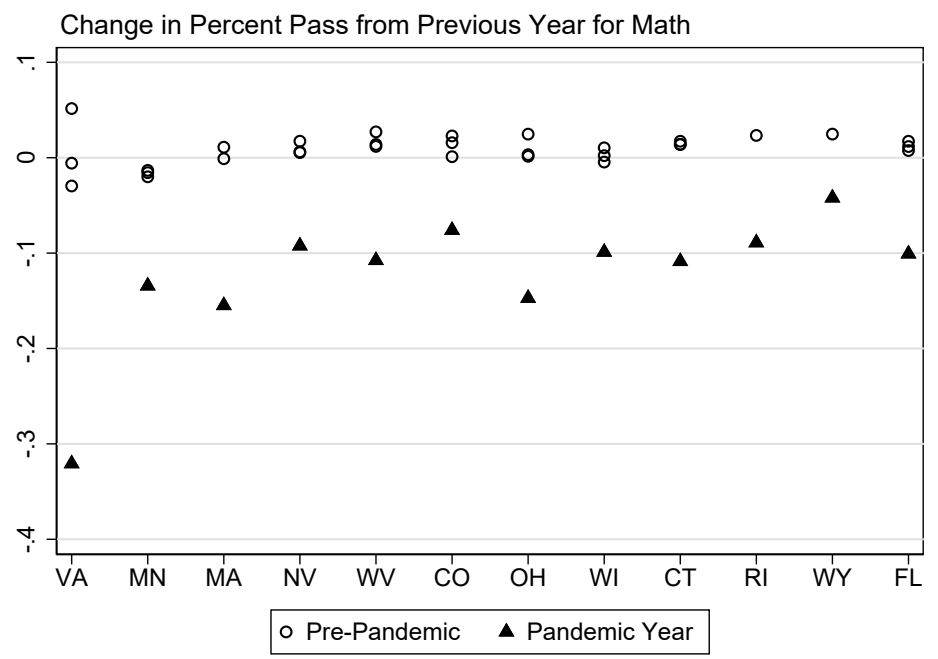

(b) ELA Scores

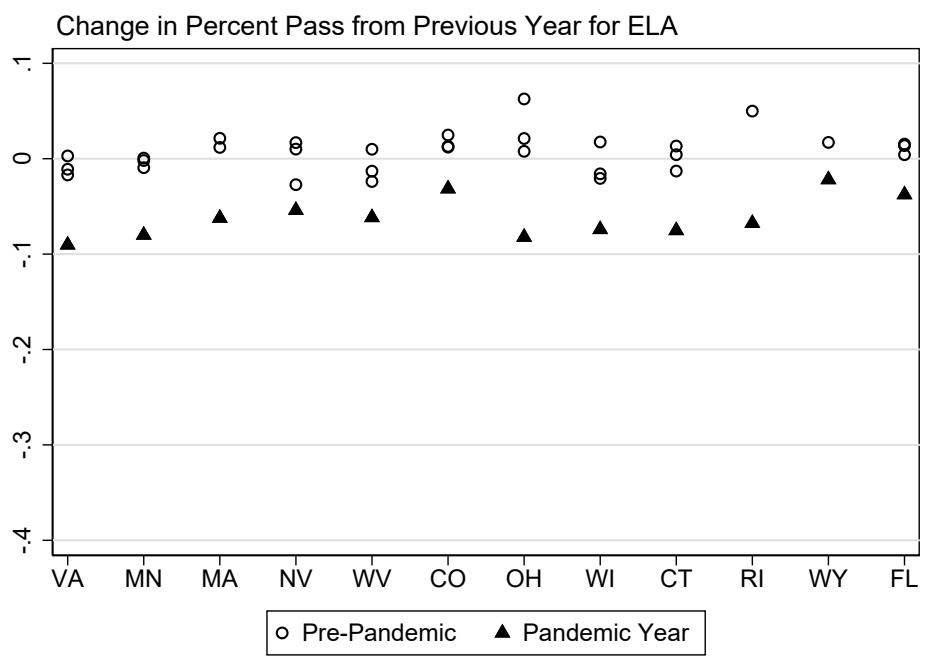

Notes: Figures show the change in percent pass from the previous year by state for pre-pandemic and pandemic years separately. All test scores are for Grades 3-8. Details of the testing by state are in Appendix B. States are in ascending order from left to right based on the share of the school year in-person. 


\title{
Figure 2: In-Person Share and Pass Rate Changes
}

\author{
(a) Math Scores
}

Change in Percent Pass from Previous Year for Math

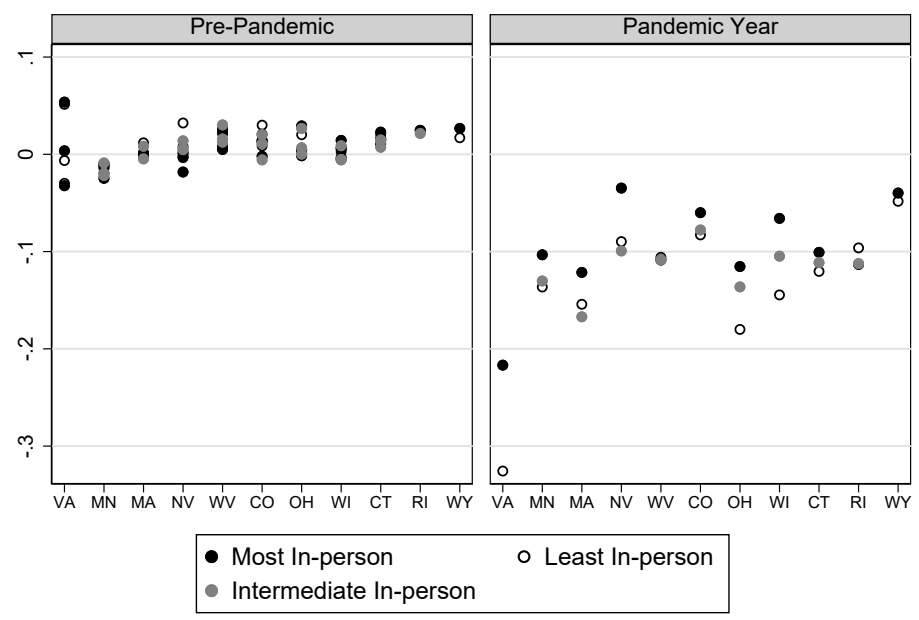

(b) ELA Scores

Change in Percent Pass from Previous Year for ELA

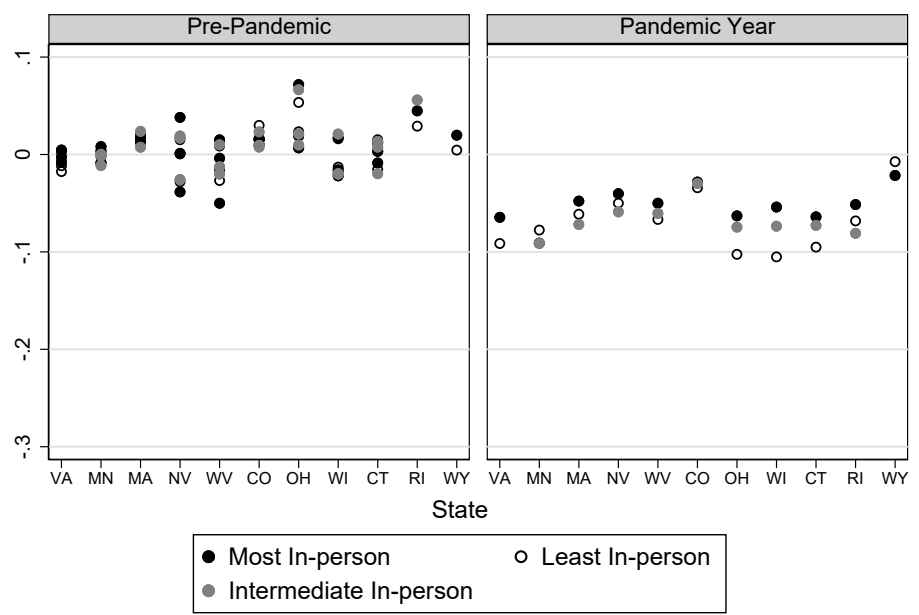

Notes: Figures show change in pass rates from the previous year by subject, state, and schooling modes for pre-pandemic and pandemic years separately. In-person learning is defined as traditional in-person school; the alternative categories are hybrid and distance learning. "Most In-Person" includes districts that were in-person at least two-thirds of the year; "Intermediate In-Person" includes districts that were in person one-third to two-thirds of the time; "Least In-person" includes districts that were in-person less than a third of the time. States are in ascending order from left to right based on the share of the school year in-person. Florida is excluded due to limited variation in in-person shares. 
Table 1: Summary Statistics by State

\begin{tabular}{lccccccccc}
\hline \hline & Districts & Avg Years & 2019 Pass Rate & 2021 Pass Rate & \% In-Person & \% Hybrid & \% Virtual & \% Black \& Hispanic & \% FRPL \\
\hline CO & 141 & 4.87 & 46.18 & 42.98 & 42.41 & 27.10 & 30.49 & 39.30 \\
CT & 177 & 4.94 & 55.84 & 48.31 & 57.41 & 31.80 & 10.78 & 39.55 \\
FL & 64 & 4.97 & 55.83 & 52.06 & 97.50 & 0.00 & 2.50 & 56.53 & 41.43 \\
MA & 352 & 3.99 & 52.06 & 45.84 & 27.49 & 52.44 & 20.07 & 31.09 & 0.00 \\
MN & 462 & 4.84 & 59.05 & 51.04 & 14.87 & 65.14 & 19.99 & 20.97 \\
NV & 19 & 5.00 & 47.25 & 41.85 & 31.64 & 48.34 & 20.02 & 38.64 \\
OH & 597 & 4.98 & 66.30 & 58.08 & 49.13 & 31.98 & 18.88 & 20.52 \\
RI & 49 & 2.98 & 47.05 & 40.28 & 58.80 & 35.75 & 5.45 & 26.49 \\
VA & 132 & 5.00 & 76.11 & 67.08 & 9.16 & 52.30 & 38.54 & 38.92 \\
WI & 414 & 4.95 & 41.16 & 33.74 & 56.93 & 21.16 & 21.90 & 35.39 & 21.80 \\
WV & 55 & 5.00 & 46.21 & 40.04 & 37.16 & 41.49 & 21.34 & 44.98 & 40.12 \\
WY & 48 & 3.00 & 56.84 & 54.65 & 93.31 & 5.80 & 0.89 & 51.28 \\
\hline \hline
\end{tabular}

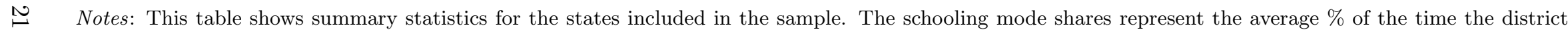
offered each schooling mode. Data on learning modes is drawn from the COVID-19 School Data Hub. Details on test score data for each state are in Appendix B. 
Table 2: Determinants of Schooling Mode

\begin{tabular}{|c|c|c|c|c|}
\hline & $\begin{array}{c}(1) \\
\text { Share In-Person }\end{array}$ & $\begin{array}{c}(2) \\
\text { Share In-Person }\end{array}$ & $\begin{array}{c}(3) \\
\text { Share In-Person }\end{array}$ & $\begin{array}{c}(4) \\
\text { Share In-Person }\end{array}$ \\
\hline Baseline Pass Rate & $\begin{array}{c}0.137 \\
(0.036)\end{array}$ & $\begin{array}{r}-0.0654 \\
(0.035)\end{array}$ & $\begin{array}{c}0.130 \\
(0.036)\end{array}$ & $\begin{array}{c}0.153 \\
(0.037)\end{array}$ \\
\hline Share Black & $\begin{array}{l}-0.450 \\
(0.036)\end{array}$ & $\begin{array}{l}-0.613 \\
(0.035)\end{array}$ & $\begin{array}{l}-0.567 \\
(0.026)\end{array}$ & $\begin{array}{l}-0.564 \\
(0.026)\end{array}$ \\
\hline Share Hispanic & $\begin{array}{c}0.369 \\
(0.0322)\end{array}$ & $\begin{array}{c}0.228 \\
(0.032)\end{array}$ & $\begin{array}{l}-0.212 \\
(0.024)\end{array}$ & $\begin{array}{l}-0.171 \\
(0.024)\end{array}$ \\
\hline Share FRPL & $\begin{array}{c}0.433 \\
(0.027)\end{array}$ & $\begin{array}{c}0.302 \\
(0.027)\end{array}$ & $\begin{array}{c}0.123 \\
(0.022)\end{array}$ & $\begin{array}{c}0.136 \\
(0.022)\end{array}$ \\
\hline Avg. Case Rate & $\begin{array}{c}0.0039 \\
(0.0006)\end{array}$ & & $\begin{array}{c}0.0032 \\
(0.0004)\end{array}$ & \\
\hline Aug. 2020 Case Rate & & $\begin{array}{c}0.011 \\
(0.0006)\end{array}$ & & $\begin{array}{l}0.00031 \\
(0.0004)\end{array}$ \\
\hline Observations & 4950 & 4950 & 4950 & 4950 \\
\hline State FE & No & No & Yes & Yes \\
\hline
\end{tabular}

Notes: This table shows regressions of the share of days in-person during the 2020-21 school year on district characteristics. The share in-person measures the share of time during the 2020-21 school year in which the district offered full time in-person instruction. COVID-19 case rates are from USA Facts. Regressions are weighted by district enrollment. 
Table 3: Schooling Mode and Test Score Changes

\begin{tabular}{|c|c|c|c|c|c|c|}
\hline & $\begin{array}{c}(1) \\
\text { Math }\end{array}$ & $\begin{array}{c}(2) \\
\text { Math }\end{array}$ & $\begin{array}{c}(3) \\
\text { Math }\end{array}$ & $\begin{array}{c}(4) \\
\text { ELA }\end{array}$ & $\begin{array}{c}(5) \\
\text { ELA }\end{array}$ & $\begin{array}{c}(6) \\
\text { ELA }\end{array}$ \\
\hline \multicolumn{7}{|l|}{ Pass } \\
\hline$\%$ In-Person & $\begin{array}{c}0.101 \\
(0.00314)\end{array}$ & $\begin{array}{c}0.143 \\
(0.00423)\end{array}$ & $\begin{array}{c}0.117 \\
(0.00578)\end{array}$ & $\begin{array}{c}0.0317 \\
(0.00236)\end{array}$ & $\begin{array}{c}0.0425 \\
(0.00315)\end{array}$ & $\begin{array}{c}0.0290 \\
(0.00430)\end{array}$ \\
\hline $\begin{array}{l}\% \text { In-Person * } \\
\quad \% \text { Black-Hisp * } 2021\end{array}$ & & $\begin{array}{c}-0.0386 \\
(0.00916)\end{array}$ & & & $\begin{array}{c}0.0475 \\
(0.00682)\end{array}$ & \\
\hline $\begin{array}{l}\% \text { In-Person * } \\
\quad \% \text { FRPL * } 2021\end{array}$ & & & $\begin{array}{c}0.0262 \\
(0.0122)\end{array}$ & & & $\begin{array}{c}0.0735 \\
(0.00910)\end{array}$ \\
\hline Observations & 11772 & 11772 & 11772 & 11795 & 11795 & 11795 \\
\hline District FE & YES & YES & YES & YES & YES & YES \\
\hline District Trends & YES & YES & YES & YES & YES & YES \\
\hline Year FE. & YES & YES & YES & YES & YES & YES \\
\hline Demog. X Year FE. & YES & YES & YES & YES & YES & YES \\
\hline Race X In-Person Sh. & NO & YES & NO & NO & YES & NO \\
\hline FRPL X In-Person Sh. & $\mathrm{NO}$ & NO & YES & $\mathrm{NO}$ & NO & YES \\
\hline
\end{tabular}

Notes: This table shows the relationship between district in-person share and test score changes. Districts that were not in-person were either hybrid or virtual. Regressions are weighted by district enrollment. 


\section{Appendix A: Additional Tables and Figures}

\section{Appendix Figure 1: Pass Rate Changes, Varying Participation Assumptions}

(a) Math Scores

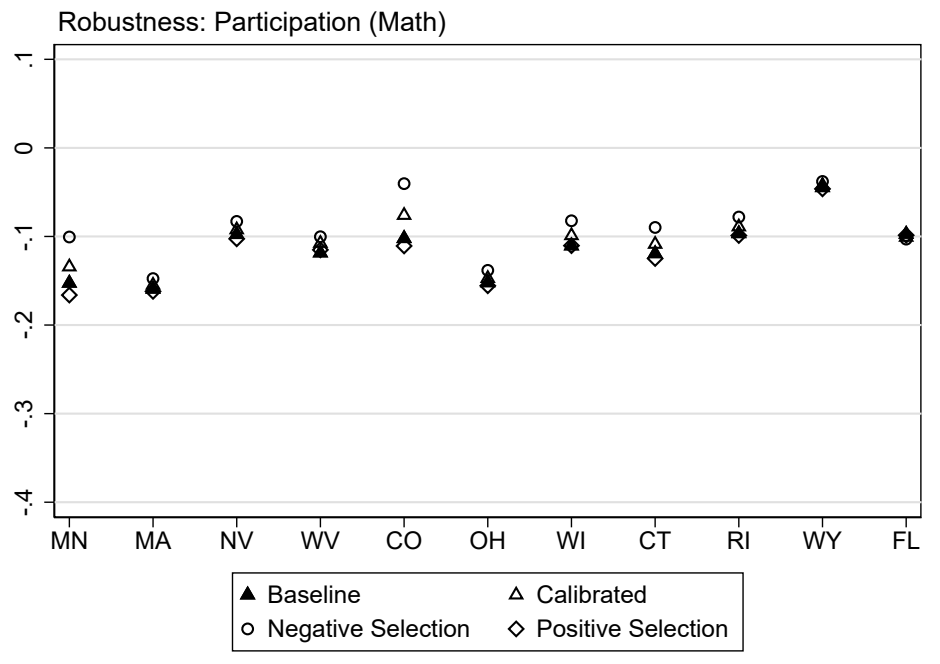

(b) ELA Scores

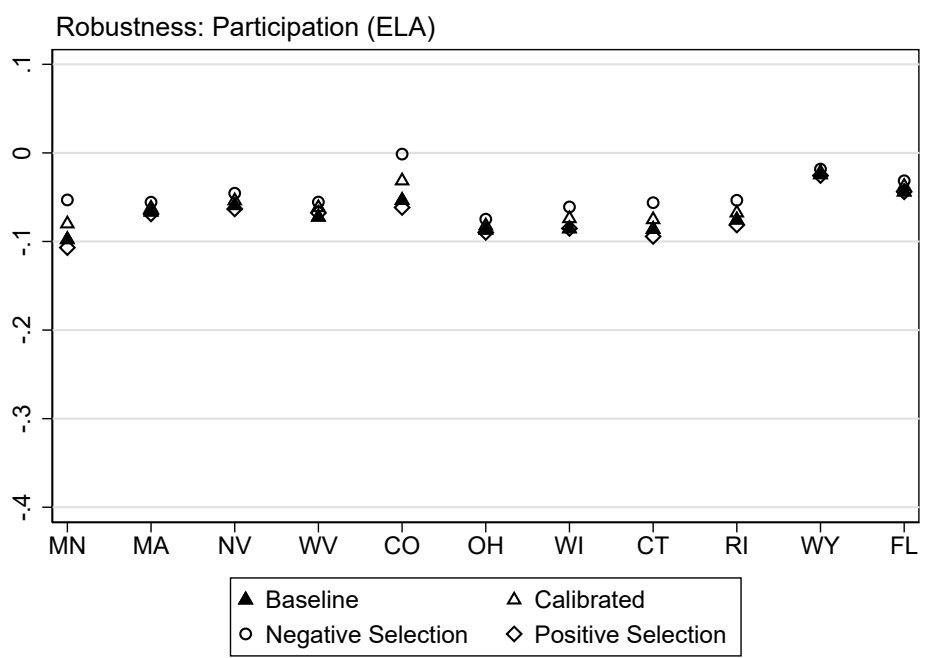

Notes: These figures show bounds on the pass rate changes under our baseline assumption and three assumptions about test scores among non-participants. The "Positive Selection" bound assumes that test takers are positively selected and the non-takers are drawn from a distribution with a mean one standard deviation below the district mean. The "Negative Selection" bound assumes the test takers are negatively selected and the non-takers are drawn from a distribution with a mean one standard deviation above the district mean. The "Calibrated Selection" models the relationship between pass rates and participation, as detailed in the discussion of robustness. Virginia is excluded due to missing participation data. 


\section{Appendix Table 1: Separating Hybrid and Virtual Learning}

\begin{tabular}{lcc}
\hline \hline & $\begin{array}{c}(1) \\
\text { Math }\end{array}$ & $\begin{array}{c}(2) \\
\text { ELA }\end{array}$ \\
Pass & & \\
\hline \% In-Person & 0.127 & 0.0516 \\
& $(0.00561)$ & $(0.00420)$ \\
\% Hybrid & 0.0408 & 0.0307 \\
& $(0.00716)$ & $(0.00535)$ \\
\hline Observations & 11772 & 11795 \\
\hline District FE & YES & YES \\
District Trends & YES & YES \\
Year FE. & YES & YES \\
Demog. X Year FE. & YES & YES \\
\hline \hline
\end{tabular}

Notes: This table shows the relationship between district in-person share, district hybrid share and test score changes. The omitted category is virtual learning. Regressions are weighted by district enrollment. All regressions include the same structure as those in Table 3.

\section{Appendix Table 2: Participation Bounding Analysis}

\begin{tabular}{lcc}
\hline \hline & Math & ELA \\
Baseline & $0.0399(0.00284)$ & $0.0415(0.00263)$ \\
Positive Selection & $0.0693(0.00280)$ & $0.0623(0.00260)$ \\
Negative Selection & $0.00531(0.00299)$ & $0.0197(0.00273)$ \\
Calibrated Selection & $0.0634(0.00280)$ & $0.0552(0.00259)$ \\
\hline \hline
\end{tabular}

Notes: This table shows our primary results about in-person shares and pass rates under the baseline and three assumptions about test scores among non-participants. The "Positive Selection" bound assumes that test takers are positively selected and the non-takers are drawn from a distribution with a mean one standard deviation below the district mean. The "Negative Selection" bound assumes the test takers are negatively selected and the non-takers are drawn from a distribution with a mean one standard deviation above the district mean. The "Calibrated Selection" models explicitly the relationship between pass rates and participation, as detailed in the discussion of robustness. Virginia is excluded due to missing participation data. All regressions include the same controls as in Table 3 


\section{Online Appendix}

\section{Pandemic Learning Mode and Student Test Scores: Evidence from US States}

\section{Emily Oster, James Okun, Rebecca Jack, \& Clare Halloran}

Appendix B. Details for State Assessments Included in Analysis, Grades 3-8

\begin{tabular}{|c|c|c|c|c|c|}
\hline State & Assessment Name & $\begin{array}{c}\text { Dates Tests } \\
\text { Administered }\end{array}$ & $\begin{array}{l}\text { Years } \\
\text { Included In } \\
\text { Analysis }\end{array}$ & $\begin{array}{l}2021 \\
\text { Participation } \\
\text { Rate }\end{array}$ & Additional Information \\
\hline Colorado & $\begin{array}{l}\text { Colorado Measures of } \\
\text { Academic Success } \\
\text { (CMAS) }\end{array}$ & Apr 12 - May 14 & $\begin{array}{c}2016-2019 \\
2021\end{array}$ & $81.8 \%$ & $\begin{array}{l}\text { In } 2021 \text {, instead of all students testing in all } \\
\text { subjects as in prior years, Grades } 3,5 \text {, and } 7 \text { were } \\
\text { tested in ELA, and Grades } 4,6 \text {, and } 8 \text { were tested } \\
\text { in math. Parents could opt their children in to take } \\
\text { both tests. }\end{array}$ \\
\hline Connecticut & $\begin{array}{l}\text { Smarter Balanced } \\
\text { Assessment Consortium } \\
\text { (SBAC) }\end{array}$ & Mar 29 - Jun 4 & $\begin{array}{c}2016-2019 \\
2021\end{array}$ & $92.4 \%$ & \\
\hline Florida & $\begin{array}{l}\text { Florida Standards } \\
\text { Assessments (FSA) }\end{array}$ & Apr 5 - Jun 11 & $\begin{array}{c}\text { 2016-2019, } \\
2021\end{array}$ & $91.8 \%$ & \\
\hline Massachusetts & $\begin{array}{l}\text { Massachusetts } \\
\text { Comprehensive } \\
\text { Assessment System } \\
\text { (MCAS) }\end{array}$ & May 10 - Jun 11 & $\begin{array}{c}\text { 2017-2019, } \\
2021\end{array}$ & $95.5 \%$ & $\begin{array}{l}\text { In } 2017 \text {, the state first administered the } \\
\text { next-generation MCAS to replace the state's } \\
\text { former MCAS; years prior to } 2017 \text { were not } \\
\text { included in analyses. }\end{array}$ \\
\hline Minnesota & $\begin{array}{l}\text { Minnesota } \\
\text { Comprehensive } \\
\text { Assessments (MCA) } \\
\end{array}$ & Mar 8 - May 21 & $\begin{array}{c}2016-2019 \\
2021\end{array}$ & $82.9 \%$ & \\
\hline Nevada & $\begin{array}{l}\text { Smarter Balanced } \\
\text { Assessment Consortium } \\
\text { (SBAC) }\end{array}$ & Feb 19 - May 19 & $\begin{array}{c}2016-2019 \\
2021\end{array}$ & $90.0 \%$ & \\
\hline Ohio & $\begin{array}{l}\text { Ohio Achievement } \\
\text { Assessment (OAA) }\end{array}$ & $\begin{array}{l}\text { Mar } 22-\text { May } 7 \\
\text { (ELA); } \\
\text { Mar 29-May } 21 \\
\quad \text { (math) }\end{array}$ & $\begin{array}{c}2016-2019 \\
2021\end{array}$ & $97.0 \%$ & \\
\hline
\end{tabular}




\begin{tabular}{|c|c|c|c|c|c|}
\hline Rhode Island & $\begin{array}{l}\text { Rhode Island } \\
\text { Comprehensive } \\
\text { Assessment System } \\
\text { (RICAS) } \\
\end{array}$ & $\begin{array}{l}\text { Mar } 29-\text { May } 14 \\
\text { (ELA); } \\
\text { Apr } 12-\text { May } 28 \\
\text { (math) } \\
\end{array}$ & $\begin{array}{l}\text { 2018-2019, } \\
\quad 2021\end{array}$ & $91.5 \%$ & $\begin{array}{l}\text { In } 2018 \text {, the state first administered the RICAS } \\
\text { assessment to replace the PARCC assessment; } \\
\text { years prior to } 2018 \text { were not included in analyses. }\end{array}$ \\
\hline Virginia & $\begin{array}{l}\text { Standards of Learning } \\
\text { (SOL) }\end{array}$ & Mar 15 - Jun 25 & $\begin{array}{l}\text { 2016-2019, } \\
2021\end{array}$ & $\begin{array}{l}\text { Not Currently } \\
\text { Available }\end{array}$ & $\begin{array}{l}\text { In 2021, the state updated its cut scores for } \\
\text { reading. }\end{array}$ \\
\hline West Virginia & $\begin{array}{l}\text { West Virginia General } \\
\text { Summative Assessment } \\
\text { (WVGSA) }\end{array}$ & Mar 29 - Jun 4 & $\begin{array}{l}\text { 2016-2019, } \\
2021\end{array}$ & $85.9 \%$ & \\
\hline Wisconsin & Forward Exam & Mar 22 - May 14 & $\begin{array}{l}\text { 2016-2019, } \\
2021\end{array}$ & $95.0 \%$ & \\
\hline Wyoming & $\begin{array}{l}\text { Wyoming Test of } \\
\text { Proficiency and Progress } \\
\text { (WY-TOPP) }\end{array}$ & April 13 - May 7 & $\begin{array}{l}\text { 2018-2019, } \\
2021\end{array}$ & $97.1 \%$ & $\begin{array}{l}\text { In } 2018 \text {, the state first administered the WY-TOPP } \\
\text { assessment to replace the state's use of the PAWS } \\
\text { assessment. }\end{array}$ \\
\hline
\end{tabular}

